\title{
Organizational factors related to occupational accidents in construction
}

\author{
J.M. Jackson Filho ${ }^{\mathrm{a}, 1}$, E.D. Fonseca ${ }^{\mathrm{a}}$, F.P.A. Lima ${ }^{\mathrm{b}}$ and F.J.C.M. Duarte \\ ${ }^{a}$ Fundacentro, Rua Capote Valente, 49, 05409-000, São Paulo Brazil \\ ${ }^{\mathrm{b}}$ Departamento de Engenharia de Produção, Universidade Federal de Minas Gerais, Belo Horizonte, Brazil \\ ${ }^{c}$ COPPE, Universidade Federal do Rio de Janeiro, Rio de Janeiro, Brazil.
}

\begin{abstract}
The purpose of this paper is to understand the influence of organizational factors on occupational accident causation. A field study was undertaken and focused on the phase of concreting the floors of a residential block in a building project in Brazil. The methodological approach was based on the analysis of carpenters' work practices and of the workers' accounts of minor falls. Observations were noted on work practices over this stage. Furthermore, interviews were conducted with the workers hired by the subcontractors and with professionals working for the main contractor. The results show that falls were related to the introduction of new building technology and its use by the workforce. The production planning and organization of activities by the subcontracted firms also led to temporary demands that were additional determining factors for falls on site. The work analysis reveals the need to consider organizational factors in prevention practices.
\end{abstract}

Keywords: occupational safety, ergonomic work analysis, accident analysis, organizational factors, outsourcing, fall

\section{Introduction}

The construction industry plays a vital role in economic development [2], and in Brazil it holds an important position within employment policies. However, it is also the sector with the greatest number of work related accidents [11], including fatal ones, as is often the case in other countries.

This state of affairs justifies the number of generally quantitative - studies based on reports of accidents or on compensation claims, which aim to analyze the causes of the accidents and establish preventative policies and procedures.

The defining characteristics of the production process (building construction in general), and of the constructions themselves, do indeed expose workers to accidents from slips, trips and falls, this is because much of the work is high above ground level and performed on irregular surfaces [10]. Grounds for these accidents are, among other factors, often reported as the lack of or the questionable quality of protection systems for falls, the equipment used (ladders), and the condition of the surfaces (internal and external). Even though it is on occasion considered possible that organizational factors are the cause of accidents, in general they are not taken into account in analyses and reports and consequently not included in the resultant statistics [10].

As organizational factors (OF) are not necessarily proximate to the accident event, they may not be mentioned in accident reports processed by safety experts, as these traditionally focus more on circumstances closer to the event itself.

Furthermore, being abstract by nature, the $\mathrm{OF}$ cannot be directly observed and they cannot be found at the scene of the accident. For instance, time pressures to meet deadlines affect behavior but do not leave physical traces once work has begun. Organizational factors may result from decisions separated by time and space and which can be translated into difficulties only when work is begun.

Haslam et al [6] propose a model of 'hierarchy of causal influences in building accidents', where the diverse causes are divided into three categories worker factors, site factors and material/equipment factors - according to their proximity to the event; these being immediate accident circumstances, shaping factors and originating factors. While the organizational factors may be present at all three times, they tend to be concentrated to the more distant

1 Corresponding author: Email: Jose.jackson@fundacentro.gov.br. 
originating factors. The organizational characteristics of the construction process - 'the continuously changing construction workplace, a peripatetic workforce, and complex project and organizational arrangement conditions' - suggest that greater efforts should be taken to reach a better understanding of their relationship to accidents and to draw up preventative measures ([16], p. 387).

Other studies have shown the influence of 'time pressure' as a risk factor in various accidents $[4,5]$. It is important to understand the organizational mechanisms that reduce workers' potentialities and lead them to 'work under pressure', whether due to planning problems, coordination problems between the various teams, or the very conditions of project execution [14].

To better understand the circumstances surrounding accidental falls during the stage of installing the moulds prior to concreting the floors, a qualitative investigation was made on the construction of a residential block in the city of Belo Horizonte, Brazil. Observations of the work performed by the team of carpenters together with accounts of accidents were the bases for the findings of this study.

\section{Research problem and methods}

A 17 storey residential block in the south of Belo Horizonte was selected as the object of study, with 56 three-bedroom apartments in 14 floors, four apartments in one floor, and two garage floors in a foundation pile-work (a pilotis).

The study was undertaken during approximately eight months, from May - December 2005, and followed the project execution of the two garage floors and the 14 other floors, which took two and six months respectively.

\subsection{Problem}

The study has its roots in an interview with the supervisor for the steel-fixing subcontractor who reported having had two falls when walking over the moulds for the concrete for the floors under construction. To try to understand the causes of these falls, which involved both other steel-fixers (like himself) and carpenters, an initial analysis was made of the work performed by the carpenters who had been responsible for fitting the moulds (and who worked for the mould fitting subcontractor).

\subsection{Methods}

The methodology applied to this study was the Ergonomic Work Analysis [EWA], which was combined with the descriptions of minor accidents given by professionals from the main contractor and employees of the subcontractors involved in the phase of concreting the floors.

EWA (as defined by De Keiser [4]) makes it possible to unravel the circumstances that lead to an accident. Rather than analysing isolated factors it seeks to analyse them in relation to know-how, to an activity as a whole.

It is this activity that guides the analysis, to the extent that it develops and brings forward information on ways of acting - the actual work - so as to develop a specific task and its inter-relation with other factors that influence its development. The activity is the mediation between the human and what he/she will produce under specific conditions (tools, work environment, organization) and it is through this that we seek to find the paradox between production demands and effects on workers.

Through analysis of the activity one can see the nature of the compromises that intervene in the elaboration of operations and also see how these compromises may have negative effects on workers' safety. This should positively contribute to meeting productivity criteria and worker safety whenever possible, seeking to pinpoint factors that contribute to a high workload, and evaluating how the workers react to this workload. At times of change, whether technological or organizational, these compromises may be especially disturbing [17].

Based on reports of "minor accidents or incidents" - considered to be of less importance by those responsible for the project - which took place during the installation of the moulds for the concreting of the floors, an explanation was sought for these event. This was done through observing the workers when performing their normal duties, and then through their explaining the circumstances leading to these "minor accidents or incidents". This made it possible to recognize the conditions that generated them, these being everything that hides the risks under a cloak of routine normality and that creates conditions ripe for latent errors [9].

The observations were on average made over three-hour sessions twice a week. In the second phase of observations, the construction of the 14 residential floors, the study followed the activities of ten workers (five carpenters and five assistant laborers) involved in the installation of the moulds and the construction of the pillars, beams and floors. 
Due to the innate restrictions of work on the construction site, specific techniques were adopted to describe the production process, the workers' activities, and to comprehend the incidental and accidental situations`. These included:

- Document analysis,

- Free observation of the activities,

- Filming, recording and photo-taking for later analysis,

- Interviews and comments from the workers were taken at their workplace, at the same time as they were performing their duties.

- Interviews and comments from the main contractor and other firms' staff.

\section{Results}

As described earlier, the field study was undertaken on an apartment block under construction. It was the first of its kind to use a new technique for supporting the moulds (prior to concreting). The study focussed on this stage of concreting the floors, in particular on the installation of the moulds.

\subsection{The introduction of a new technique for the floor concreting}

The project planned to use a rigged concrete structure with a flat floor without delineating beams for the walls and the use of a ribbed floor. In projects prior to this, the firm had used pre-cast moulds supported on wooden joists to construct the ribbed floor. However, the site engineer and the subcontractor responsible for installing the moulds chose to use a new support system, metal trusses for concrete floors, thereby substituting the wooden joists.

According to the supplier, the system was selected due to a series of advantages, particularly for the performance of the operation. These included:

- Removal of the moulds while maintaining the position of the supports, thus saving time on the project execution.

- Saving labour in the installation and removal of the moulds, as they do not require specialized labour or special tools.

- The prevention of defects in the concrete flooring, as the moulds are removed while maintaining the support.

- Facilitating perfect structural leveling.

- Assuring stability of the support through vertical and horizontal locking

- Saving material through the use of beams and steel trusses.
- Ease of access under the floor above for movement of people and materials and increased safety for workers.

- Fewer accidents involving nails and hammers.

The workers themselves regarded the new technique as advantageous, as it would allow increased productivity and therefore greater remuneration. Their earnings were directly related to their productivity.

At the start of the process (installing the moulds for the garage floors) and as described before, there were several accidental falls during the workers' (carpenters, labourers, steel-fixers) movements over the moulds, and these accidents were perceived to increase in gravity.

\subsection{Description of the stage of concreting the floor and beams}

The stage of concreting the floors and beams consists of three operations: the fitting of the moulds, the installation of the iron and the concreting of the beams and floors. The carpentry team was given the job of fixing the metal trusses and putting the moulds over them before the steel-fixers arrived to install the iron before concreting. After this, the carpenters had to remove the supports, trusses and moulds, which were then moved to the next floor.

Over the course of the construction of the apartments' floors the team consisted of six carpenters and six labourers, with one carpenter and one labourer being responsible for the stairway.

\subsection{The falls}

Many workers - carpenters, labourers, builders and those employed by the structural subcontractor - described that they had fallen when walking on the moulds placed on the new system. Five accidents were reported to the researcher during the research period although not formally reported.

In this project, the first large-scale one of its kind to use metal trusses as supports, the moulds placed on them were not correctly fixed. The main reason for this was due to the design of the system, particularly the dimensions of the truss fitting, as the width of the fitting $(25 \mathrm{~mm})$ in the truss was only large enough to fix the foot of the mould $(40 \mathrm{~mm})$. Any factor that impeded the correct fixture made the mould unsafe.

Two situations were observed:

- The need to secure the structure with wire: when this new technique was selected the engineer and constructor envisioned that the structure 
would be stable by merely supporting it on the external beams (made of wood). However, throughout concreting the first floors, one could note that when the concrete was vibrated the structure as a whole became unstable and mortar was lost. To ensure the stability of the whole, the workers joined lateral beams to the metal structure using wire. Consequently, as the wires had to pass through the trusses supporting the moulds they impeded the fixture between them thus making the moulds unsafe.

- Dirt in the moulds: from the fourth floor on, it was noted that mortar residue, leftover in the casings due to lack of time, also impeded their fixture in the trusses.

In order not to fall, the more experienced workers learnt that it was necessary to step in the centre of the moulds, forcing them to fit in. If this was not done, the mould would overturn and the worker would fall from approximately three meters' height.

\subsection{Explanations of the falls}

In spite of the problems of fit between the moulds and support, several reports by workers, site managers and the safety technician alleged a lack of attention and care by the workers as one cause of the accidents. They fell due to "not walking properly", although no special training had been given them regarding "the correct way to walk on the moulds". For example, when commenting on an accident, the contractor's safety technician stated:

"He stepped at the very edge of one of the pre-cast concrete moulds...it ended up overturning as he had stepped on it incorrectly, stepped on it in the wrong way".

Other accounts linked the falls to "rush" in the project execution and loading equipment and raw materials. The "rush" could be blamed on the individuals. The observations and interviews showed, however, that above all it was defined by external factors and was in general organizational in nature. These comments by two employees serve as illustration:

"I was putting in the slabs, I went and stepped wrong on one, it went over and I fell [...] It's hard. It's the rush [...] Rush is the enemy of perfection" (carpenter).

"For you to step right you have to know that you always have to step on the middle of the slab, you can't get distracted, if you step on its edge it'll overturn, you know? So, you have to always make sure and check that you step in the middle of the slab. If a guy is in a rush, or is maybe carrying something that makes it difficult for him to see [shows carrying a support]. He's carrying something heavy, like carrying iron up there [referring to the riggers], and he goes and falls. He has to be careful, check in front a bit [stretches his arm to move the load away from the body in order to see] and walk slowly" (carpenter's labourer).

\subsection{Organizational factors related to the accidents}

For the structural design of the building, it had been decided that the floors would be rigged using a specific kind of mould made by a particular firm.

In the construction company's organizational structure, the site engineer was responsible for hiring the subcontractors and for controlling the project execution.

The site engineer invited bids from companies for the contract to provide work and materials. The successful sub-contractor (the subject of this study) had received the structural design from the engineer. The structural designs for the moulds were generic, there had been no specifications for the particular type of support to be used. It was the responsibility of the sub-contractor to define the means of executing the work, installing the moulds and surface laying (without specific plans), using the structural design as a base.

The manufacturer of the moulds recommended the project to the company which supplied the new type of support for the moulds and then invited the engineer responsible to visit a small-scale project where the new technique was being used. The objective of the visit was to analyze its technical viability for that particular project.

Once the new support had been checked regarding technical viability, the engineer asked the subcontractor to check the economic viability together with the use of the new support. After the subcontractor had approved its use, the engineer and subcontractor decided to use the new kind of support for the ribbed floor for the structural design. After hiring the support they received detailed plans from the manufacturer of the support of the floors and for fitting the moulds for the project described in this study.

So, they decided to use the metallic trusses as a support for the first time ever in a large-scale building project; the lack of experience in large-scale sites was not considered in their decision making. Because this system was chosen for the project, various workers were put at risk of accidental falls until they discovered the correct way of walking on the centre of the slabs. 
Due to the turnaround of workers in various sites of the contractor some of the falls (two cases) involved newly arrived workers who were evidently unaware of the risks.

Three factors from the contract agreed upon between the construction firm and the subcontractors led to the project conditions for the installation of the moulds and the workers" "rush":

- For the project to be viable, in other words for it to stay within its budget, the subcontractor could only hire one set of moulds.

- The maximum deadline for delivery of the concreted floor was 10 days.

- There was a small number of available steelfixers.

The execution of the numerous activities for concreting the floors was also conditioned by other factors like the fact that concrete needs four days to cure, and that Saturdays and Sundays are days off.

Due to this, the carpenters' workload varied greatly depending on the day of concreting. If undertaken on a Thursday (the ideal day), by the start of the following week the carpenters could work almost sequentially without having to perform multi-tasks. If this did not happen, and the concreting was done for example on a Monday, the workers would spend a lot of idle time while waiting for the concrete to cure until they could remove the moulds. This meant that the removal of the moulds, the transportation and rigging all had to be done at the same time. They would then have to work in a "rush" in order to meet the deadlines so as to make up for the "lost time".

In addition to this, the team installing the moulds were constrained by the production capacity of the steel-fixers, who in turn were constrained by their managers (a result of the negotiation between the construction firm's engineer and the subcontractor) and by the time limit for their duties before the concreting of the floors and pillars.

\section{Discussion}

\subsection{Organizational factors in construction operations and accidents}

Civil construction, particularly in the sub-sector of building, is a craft, even though there is a first introduction of pre-cast products and heavy equipment in design execution. There are certain factors that explain the low level of "industrialization" of the sector in Brazil: the lack of standardization of products and materials, the low cost of labour, and the organization of the process by subcontractors. The study presented here portrays the characteristics of civil construction in Brazil and offers suggestions on how to understand the relationship between the 'method of production' and the prevalence of accidents in the sector.

The organization of the construction was deliberately based on farming out services to subcontractors. For its defenders, the reason for this is the assurance of quality, as they are specialists who provide the services. However, subcontracting and contracting out are inadequate forms of management and work organization, as their main aim is to reduce provisional and work-related social costs [8], to increase "pressure on productivity" or to reduce Occupational Health and Safety (OHS) costs [7]. It can be seen from this study that subcontracting can be associated with accident causation.

The staff of the construction firm, although responsible for the project (including the safety of subcontractors' employees) inadequately administered the construction process. Instead, they merely monitored its execution. The contracts that were agreed with the subcontractors created conditions of risk during the concreting operations due to the tight deadlines and reduced budget. The completion of work in reduced time frames by the installation subcontractor's employees, and of work in parallel to the steel-fixing subcontractor made it necessary to meet the contractual clauses. In this manner of organization, with only a small margin to work with, the "rush" to meet the deadlines was imposed on the subcontractors and on the workers.

Our observations confirm the findings of Suraji et al [14] which, after studying Health and Safety Executive (HSE) accident reports in England, show that many 'accidents in construction projects involve inappropriate construction planning, inappropriate construction control, inappropriate construction operation, inappropriate site condition, and inappropriate operative action' (p. 334).

The findings also confirm the inversely proportional relation between the frequency of accidents and the size of the companies [12].

\subsection{Organization of the design process and accidents}

Design can influence construction occupational health and safety, and so it may be a fundamental arena in which to build prevention $[1,15]$. Design practices have direct influences on OHS, associated to the definition of construction process and contracting, and indirect ones associated to design itself (materials, specifications, etc.) ([1] p.594). 
In our case, the workers' falls from the floors under construction were associated with the system design; particularly the truss fitting, which did not fix the moulds adequately.

The system, which was based on a product available in Europe, had a smaller fitting and was not suitable for a large-scale building. The supplier of the system was responsible for the accidents, equally as those who chose to use it in the construction.

By accepting the subcontractor's new technique, whose application had never been tested, the engineer, together with the mould-fitting subcontractor, became responsible for its use and its consequences, including the accidents. The construction was basically a pilot for the new technique. The question is how such a little known technique could be used without safety measures or even a test-run?

The choice of this technique was a design decision, and this makes it necessary to reflect on the complete process of the production of a building, from design to completion to ensure the safety of all the workers involved.

\subsection{The contribution of EWA}

Quantitative methods for understanding the accidents and their relation to organizational factors are relatively efficient [10]. The difficulty in describing the influence of the organizational factors and their mechanisms is due to the design of the accident studies, which for the most part are based on statistics from accident reports or on analysis of accounts contained in these same reports.

The adoption of qualitative methods seems to be appropriate to define not only the root factors, but also the relations between them. In addition, as in this study, they can make a significant contribution to the prevention of further accidents.

The ergonomic work analysis of the carpenters' work made it possible to detect not only the root problem behind the workers' falls and the use of the truss system, but also the contradictions of the construction planning and organization. These concerned costs and deadlines and exposed numerous workers to risk of accident.

Even when presented with the influence of the organizational and design determiners on the creation of accident conditions, the workers still considered themselves to be responsible for the accidents they suffered. Lack of attention and care as well as unsafe acts permeated not only discussion among the company technicians but also among the workers them- selves, which previously has been reported in other studies (e.g. [13]).

These subjective (psychological) explanations are strengthened by the fact that the workers had learnt how to walk over the moulds, meaning that the falls became less "justifiable" or "understandable" as if "knowing the correct way of walking" were enough to be able to walk safely. Between the knowledge and the action there is no reliable solution, as if the act of walking were directly linked to the knowledge of how to walk, with no circumstantial influence from the material and organizational context in which the activity is undertaken: carrying large or heavy objects (moulds, steel), being in a hurry, etc. The workers blamed themselves for their falls, even after finding strategies to walk over the moulds. The knowledge and corporal skill that they developed were effective in the majority of situations, but could be insufficient in other situations. While learning to walk safely was a relatively efficient method of preventing falls, it also highlighted the need for the situation to be changed. In the attempt to understand the causes to accidents, the situated analysis of work activities, the object of EWA, opposes the analysis of unsafe acts that automatically implies a value judgment on workers' practice. Faced with the recent resurgence of interest in analysis of unsafe acts [3], the methodological perspective of EWA may be able to contribute to understanding the socio-technical 'production' of accidents. In fact, as stated by Woods \& Cook [18], 'progress on safety depends on understanding how practitioners cope with the complexities of technical work' and, in the case of accidents, on understanding how the adjustment mechanisms are broken.

\section{References}

[1] M. Behm, Linking construction fatalities to the design for construction safety concept, Safety Science 43 (2005), 589611.

[2] M. Behm, Construction sector, Journal of Safety Research, 39 (2008), 175-178.

[3] Choudhry and D. Fang, Why operatives engage in unsafe behaviour: Investigating factors on construction sites, Safety Science 46 (2008), 566-584.

[4] V. De Keiser, Work analysis in French Language ergonomics: origin and current research trends, Ergonomics 34 (1991), $53-669$.

[5] H.M. Gravseth, Accidents in construction-the search for preventable causes, in: Safety in Building and Construction Industries: State of the art and perspectives no prevention, report from a Nordic occupational safety research seminar in Copenhagen, Nordic Council of Ministers, Copenhagen,2004, pp.19-24. 
[6] R.A. Haslam, S.A Hide,A.G.F. Gibb, D.E. Gyi,, T. Pavitt, , S. Atkinson and A.R. Duff, Contributing factors in construction accidents, Applied Ergonomics 36 (2005), 401-415.

[7] R. Johnstone, M. Quinlan and C. Mayhew, Outsourcing risk? The regulation of OHS where contractors are employed, Comparative Labour Law Policy Journal 22 (2001), 351-393.

[8] A.C. Laurel, Research on work and health in Latin America: The perspective of social medicine, New Solutions 4 (1995), 53-63.

[9] F.A.P. Lima, Formação em ergonomia: reflexões sobre algumas experiências de ensino da metodologia de análise ergonômica do trabalho.in: Trabalho, educação e saúde: um mosaico em múltiplos tons, C. Kiefer, I. Fagá and M.R. Sampaio, eds., FUNDACENTRO, São Paulo, 2000, pp. 133148. (In Portuguese)

[10] H.J Lipscomb, J.E. Glazner, J. Bondy, K. Guarini, and D. Lezotte, Injuries from slips and trips in construction, Applied Ergonomics 37 (2006), 267-274.

[11] R.M.N. Mangas, R, C.M. Gómez, S.M.F. Thedim-Costa, Acidentes do trabalho fatais e desproteção social na indústria da construção civil do Rio de Janeiro, Revista Brasileira de Saúde Ocupacional 33 (2008), 48-55
[12] D. Mc Vittie, H. Banikin and W. Brocklebank, The effects of firm size on injury frequency in construction, Safety Science 27 (1997), 9-23.

[13] F. Oliveira, A persistência da noção de ato inseguro e a construção da culpa: os discursos sobre os acidentes de trabalho em uma indústria metalúrgica, Revista Brasileira de Saúde Ocupacional 32 (2007), 19-28.

[14] A. Suraji, A.R. Duff and S.J Peckitt, Development of causal model of construction accident causation, Journal of Construction Engineering and Management 127 (2001), 337-44.

[15] T.M. Toole and J. Gambatese, The trajectories of prevention trough design in construction, Journal of Safety Research 39 (2008), 225-230.

[16] H.E. Van der Molen, E. Kongsveld, R. Haslam and A. Gibb, Editorial. Ergonomics in building and construction: Time for implementation, Applied Ergonomics 36 (2005), 387-389.

[17] ] A. Wisner, Understanding problem building: ergonomic work analysis, Ergonomics 38 (1995), 595-605.

[18] D.D. Woods, and R.I. Cook, Nine steps to move forward error, Cognition, Technology \& Work 4 (2002), 137-144. 